\title{
A MODEL FOR TIME- AND BUDGET-CONSTRAINED ACTIVITY DEMAND ANALYSIS
}

\author{
by \\ Kara Maria Kockelman \\ Assistant Professor of Civil Engineering \\ The University of Texas at Austin \\ 6.9 E. Cockrell Jr. Hall \\ Austin, TX 78712-1076 \\ kkockelm@mail.utexas.edu \\ Phone: 512-471-0210 \\ FAX: 512-475-8744
}

Transportation Research B (3): 255-269, 2001 


\begin{abstract}
This paper describes and demonstrates the derivation of a system of demands for activity participation by applying microeconomic theory in a time-price setting. Both time and money constraints are incorporated explicitly and the integer nature of demand observations is accommodated via a multivariate negative binomial stochastic specification. A model based on this theory is calibrated, providing estimates of income, discretionary-time, and cross-time elasticities. The results reject a constant travel time hypothesis but do not reject a hypothesis of no income effects on total activity participation.
\end{abstract}

\title{
KEY WORDS
}

Traveler behavior models, time constraint, utility maximization, simultaneous equations, activity participation, multivariate negative binomial 


\section{INTRODUCTION}

This paper presents a new methodology for modeling out-of-home activity participation. Over the years, travel behavior has been modeled in a number of ways. Many of the earliest models were developed primarily for prediction; their virtue is that they are easy to apply. Later models are generally superior, often arising from hypotheses of human behavior (e.g., Becker 1965, Domencich and McFadden 1975) and focusing on causation. Some of the most plausible travel models acknowledge simultaneity in decision-making by avoiding strictly sequential estimation (e.g., Damm and Lerman 1981, Kitamura 1984), hypothesizing distinct behavioral mechanisms (e.g., Train and McFadden 1978, Yen, Mahmassani, and Herman 1998), and/or suggesting new ways of adhering to microeconomic theory (e.g., Mannering and Winston 1985). However, shortcomings in existing models persist. For example, behaviorally-based time-use research remains largely theoretical (e.g., Jara-Díaz 1994); models of simultaneous decisions that are consistent with utility maximization tend to be of discrete choices (e.g., Train et al. 1987); many models of jointly estimated demand responses lack behavioral bases (e.g., Golob and McNally 1997, Lu and Pas 1997); and supply-side variables have been lacking in models of trip demand (e.g., MTC 1996, ITE 1994). The existing literature also does not consider integer consumption of multiple goods based on a continuous and cardinal latent response in a microeconomically rigorous framework.

These deficiencies are in notable contrast to the model developed here, which is based on microeconomic theories of rational behavior and utility maximization and which incorporates constraints on time and money. Given an indirect utility specification, parallels to Roy's Identity (Roy 1943) produce a system of long-run demand equations. Empirical application is accomplished via a multivariate negative binomial system of regression equations, recognizing 
unobserved heterogeneity in behavior and correlation in this information across demand types for a single observational unit, the household. The result is a microeconomically rigorous model of choice that supplies estimates of activity demands, welfare effects, cross-time demand elasticities, values of time, and other behavioral properties.

\section{METHODOLOGY}

\section{Microeconomic Foundations \& Roy's Identity}

Outside of transportation, there are many examples of microeconomically rigorous simultaneous-equations models of demand for goods and services; however, time constraints are not considered. [See, for example, Lau (1986), Deaton (1987), Deaton and Muellbauer (1980), Stone (1954), and Pollack and Wales (1978).] In a general formulation of the utilitymaximization problem, a person or household may be assumed to derive its welfare (i.e., utility) from consumption of/participation in a vector of distinct, out-of-home activities $\vec{A}$ (indexed by $i$, which may be location-, time- and mode-specific, and which includes the household's work activities), the time spent participating in each of these activities $T_{i}$ (with $T_{w}$ representing the work activity's time), the total time spent accessing all of these activities $\vec{t} \vec{A}$ (where $\vec{t}$ is the vector of fixed travel times to access the activities), and consumption of all other goods $\vec{Z}$. It is helpful to think of the consumption/decision variables in this problem as rates; for example, one activity might be the number of shopping trips in the local neighborhood per day. Under the general model, households are subject to unearned income $\left(Y_{u n}\right)$ and available-time $(H)$ constraints which are also rates (e.g., dollars per day, hours per day), and these constraints lead to trade-offs between consumption of the different goods. In equation form, the problem can be written as the following: 
$\operatorname{Max}_{\vec{A}, \bar{Z}, \bar{Z}} \operatorname{Utility}(\vec{A}, \vec{T}, \vec{t} \vec{A}, \vec{Z})$
s.t. $\vec{P}_{A} \vec{A}+\vec{P}_{t r v l} \vec{A}+\vec{P}_{Z} \vec{Z} \leq Y_{u n}+w T_{w}, \sum_{i} T_{i}+\vec{t} \vec{A}=H$, and $\vec{A}, \vec{T} \& \vec{Z} \geq 0$.

Note that time spent for activity participation is of two types: travel to non-home sites $\left(t_{i}\right)$ and during participation itself $\left(T_{i}\right)$; both of these enter explicitly in the direct utility function, though only the participation time, $T_{i}$, is an endogenous variable. The work activity contributes to the income budget level via the wage earned, $w$; but participation in most other activities is likely to cost money (with $P_{t r v l, i}+P_{A_{i}}$ representing the monetary price per unit of participation in activity $i$, due to travel costs and direct participation costs). There is an equality in the time constraint since all time not spent accessing and participating in activities outside of the home is time spent in at-home activities.

The general model is subject to various modifications. For example, if one wishes to focus on discretionary activity choices and assume work and income exogeneity in such decisions, one will not explicitly model work as an activity and will substitute total income, $Y$, for unearned income, $Y_{u n}$, and discretionary time, $T_{d}$ (total time minus, for example, work and school time), for total time, $H$. Also, there are many other constraint possibilities; for example, minimum participation-time constraints may exist for certain activities and only fixed levels of consumption may be permitted (such as working or going to school five times per week).

In practice, a closed-form/analytic solution to constrained maximization of direct utility functions of several goods is rare, because solution of the Lagrangian equation's set of first-order conditions is often intractable. In order to derive a system of (optimal) demand equations, it has 
been found significantly more convenient to work with the indirect utility function, as defined in Eq. 2 (with arguments defined as for Eq. 1).

$$
\begin{aligned}
\text { Indirect Utility } & =\{\text { Max Utility } \mid \text { Budget \& Time Constraints }\} \\
& =v\left(\vec{P}_{A} \vec{P}_{t r v l}, \vec{P}_{Z}, \vec{t}, Y_{u n}, w, H\right)
\end{aligned}
$$

By beginning from a specification of indirect utility - which is not directly observable, Roy's Identity (Roy 1943) provides equations of demand - which are observable. Under a twobudget set-up, Roy's Identity continues to hold ${ }^{1}$ - but more restrictively than in the typical, single-budget framework (see Kockelman [1998] for a derivation). Given a functional specification for indirect utility, $v$, as well as exogenously determined available time $(T)$ and income $(Y)$ constraints, the relations one can use to identify optimal demand, $A_{i}{ }^{*}$, are shown in Eq. 3. Figure 1 illustrates the general relationships of the model framework via a flowchart.

Roy'sIdentity: $\quad A_{i}^{*}=-\frac{\frac{d v}{d t_{i}}}{\frac{d v}{d T}}=-\frac{\frac{d v}{d\left(P_{t r v l, i}+P_{A_{i}}\right)}}{\frac{d v}{d Y}}, \forall i$,

where $A_{i}^{*}=$ Optimal, long - run rate of consumption per period, $v=$ Indirect utility, $t_{i}=$ Travel time to Activity $i$, $T=$ Time available per period, $P_{t r v l, i}+P_{A_{i}}=$ Unit Price to participate in Activity $i$ (due to travel \& participation costs), $\& Y=$ Income available per period.

The derivation of the entire system of demands from a single indirect utility specification imposes many cross-equation parameter constraints automatically (because many parameters are likely to show up in two or more of the demand equations). When income and time budget levels are exogenous, the derivation of optimal demand levels is reasonably straightforward, and the value of time can be estimated using the ratio of derivatives of indirect utility with respect to 
available time and income. However, income and discretionary time may be endogenous to the decision to participate in non-work/discretionary activities because many households are able to choose how much time to spend working (earning income while giving up discretionary time) when determining the levels of other activities they might engage in.

If unearned income and total time available are observed, the identities allowing one to identify demands require that derivatives of indirect utility with respect to total time $(H)$ and unearned income $\left(Y_{\text {un }}\right)$ be used in Eq. 3, instead of available time $(T)$ and income $(Y)$. And one can use the following relation to estimate the value of time:

Value of Time $=\frac{\lambda_{\text {Time }}}{\lambda_{\text {Money }}}=\frac{d v / d H}{d v / d Y_{\text {un }}}$

\section{Theory-Implied Constraints}

In order for demand equations to be consistent with microeconomic theory and common sense, they generally must satisfy several constraints. [See, e.g., Varian (1992).] For example, there are non-negativity and non-satiation constraints on consumption, implying non-negative demand and summability of expenditures. In a system of activity-demand equations explaining all uses of a time budget, summability should be imposed to ensure that results are consistent with reality (e.g., a 24-hour day). However, if one is considering only the number of activities

accessed, rather than the amount of time spent in each ${ }^{2}$, summability's imposition across traveltime expenditures puts the focus on allocating an exogenous total travel time, rather than allocating total time available. Thus, summability would be unnecessarily limiting and is not imposed here. 
Another functional constraint derives from the preference for price extremes over balanced prices; this preference is manifest in the indirect utility function's quasiconvexity and the monetary expenditure function's concavity, with respect to prices. Moreover, expenditures are expected to be homogenous of degree one, so pure inflation should not affect behavior. And, theoretically, symmetry of compensated cross-price effects should also hold (Slutsky 1915). However, humans directly experience time use, including travel time, so time expenditures are arguments in the direct utility function. This aspect of time use nullifies these three constraints in a time-expenditure setting; so quasiconvexity, homogeneity, and symmetry with respect to time costs should not be imposed.

Preference separability is a restrictive feature generally implied by the neglect of one or more goods - along with their price (or time) information; such neglect shifts the modeling focus to substitution and trade-offs within a subset of consumption over an exogenously determined subset of the budget [see, e.g., Deaton and Muellbauer (1980)]. However, if prices of all nonconsidered goods are the same for all consumers, an assumption of preference separability is unnecessary. In the empirical application which follows, price information is not available; therefore, only a single system of demand equations is derived - on the basis of travel times, and an assumption of price constancy across the cross-sectional sample of households is made. Price invariance across observations means that separability is not an implicit assumption and price effects are not identifiable empirically. 


\section{EMPIRICAL APPLICATION}

\section{Data Set}

To test the proposed model, the 1990 Bay Area Travel Surveys (BATS) - which detail trip-making and out-of-home activity participation for over 10,000 households in the San Francisco Bay Area - are used. Here the focus is on the household as a unit, rather than intrahousehold trade-offs and decisions; so the available time and income budget apply to the entire household. Lack of wage and price information for these households necessitates an assumption of work exogeneity and a focus on discretionary activity participation, as well as estimation of a single system of demand equations - based on time derivatives of indirect utility. The variables used are described in Table 1.

The definition and distinction of demands is not based on type of discretionary activity (e.g., dining versus recreational). Instead, all discretionary activities are grouped together and iso-opportunity contours distinguish the latent quality of activity. The use of such contours acknowledges the fact that people travel further than they need to in an effort to enhance the quality of their chosen activity. Since this quality dimension is latent in the data set, activities are segmented by how many intervening opportunities household members pass up in order to access them. Four activity demands are considered: discretionary activity participation in the opportunity environment immediately surrounding one's home (defined as the area containing the closest 60,000 jobs), the nearby area (the next 240,000 jobs), locations within moderate range (the next 600,000 jobs), and far-away locations (the remaining 1.1 million jobs) ${ }^{3}$. Travel times for these activity groups represent average travel times to access the four different isoopportunity sets, with times measured relative to a household's home location. Clearly, there 
will be high substitutability among these four activity classes; this feature can be accommodated using a flexible system of demand equations

\section{Model Specification}

A modified version of Christensen et al.'s translog form (1975) represents the indirect utility function estimated here, as shown in Eq. 5. This form provides substantially more functional flexibility than Cobb-Douglas or Rotterdam specifications (Greene 1993, Christensen et al. 1975) and models substitutes well (Caves and Christensen 1980).

$$
\begin{aligned}
& \text { Indirect Utility }=v \approx \text { Translog }\left(\vec{t}, T_{d}, Y\right), \\
& \qquad \begin{array}{l}
v=\alpha_{o}+\sum_{i} \alpha_{i} \ln \left(t_{i}\right)+\sum_{i j}(1 / 2) \beta_{i j} \ln \left(t_{i}\right) \ln \left(t_{j}\right)+ \\
\quad \sum_{i} \gamma_{i} \ln \left(T_{d}\right) \ln \left(t_{i}\right)+\sum_{i} \gamma_{i Y} \ln (Y) \ln \left(t_{i}\right)+\gamma_{T Y} \ln \left(T_{d}\right) \ln (Y)
\end{array}
\end{aligned}
$$

The optimal demand levels, which result from application of Roy's Identity (with respect to time) to the above formulation, are the following:

$$
\text { So, } X_{i}^{*}=\frac{-\left(1 / t_{i}\right)\left(\alpha_{i}+\sum_{j} \beta_{i j} \ln \left(t_{j}\right)+\gamma_{i Y} \ln (Y)+\gamma_{i T} \ln \left(T_{d}\right)\right)}{1 / T_{d}\left(\sum_{j} \gamma_{j T} \ln \left(t_{j}\right)+\gamma_{T Y} \ln (Y)\right)},
$$

where $t_{i}=$ Travel Time to Activity $i, Y=$ Income, $\& T_{d}=$ Discretionary Time Available. $\beta_{i j}=\beta_{j i} \forall i j \& \gamma_{T Y}=1$ (for identifiability of parameters).

Notice that the number of parameters in this modified translog system increases quadratically with the number of good types considered. The system of equations requires the estimation of $3 I+I(I+1) / 2$ parameters.

\section{Statistical Specification}


Though cardinal in nature, observed activity-participation demands $\left(X_{i}\right)$ are plainly discrete in limited-period data sets. One may expect that continuous and smoothly differentiable preference and demand functions underlie observed behavior, since households are typically free to optimize their choices over relatively long periods of time. This is the assumption made here, and a link to a model of cardinally ordered discrete demand levels is provided via assumption of a Poisson distribution (Eq. 7).

$$
\begin{aligned}
& X_{i} \sim \operatorname{Poisson}\left(\lambda_{i}\right), \\
& \text { where } \lambda_{i}=X_{i}^{*}=f_{i}\left(\vec{t}, Y, T_{d}\right) .
\end{aligned}
$$

The Poisson distribution arises naturally from counts of independent events that occur at a specified rate, so it is a plausible distributional assumption if household members make trips at randomly and independently selected times throughout their window of discretionary time. Due to coordination, scheduling and other constraints (e.g., see Hägerstrand 1970, Recker 1995, and Ettema et al. 1995), it is unlikely that this condition holds. However, the Poisson may still characterize activity participation counts, particularly over longer periods of time, as the shortterm/daily realities of trip chaining and activity coordination take on less importance relative to long-run behavior.

The Poisson also can be mixed rather easily with a gamma distribution - producing a negative binomial, and capturing unobserved heterogeneity across different households while permitting overdispersion in the data. The negative binomial assumption has been used in empirical work for several decades. For example, Chatfield et al. (1966) used a single negative binomial regression equation to model household purchases. And Rao et al. (1973) model the number of boys and the number of girls born to a pair of parents as symmetric binomials conditioned on a negative binomial for the total. More recently, Shankar et al. (1998) have 
applied a random-effects negative binomials for roadway accident models, and Hausman, Leonard, and McFadden (1995) sequentially estimate the choice of recreational sites as a multinomial conditioned on total number of trips, where the total is a fixed-effects Poisson. The use of the same gamma error term across all demands generated by a single household allows cancellation of these terms in the probabilities of a multinomial (which is conditioned on a negative binomial for total demand), as illustrated in the following equations ${ }^{4}$ :

If $X_{i} \sim \operatorname{Poisson}\left(\lambda_{i}=X_{i}^{*} \varepsilon\right)$, and

$\sum_{i=1}^{I} X_{i}=X_{T} \sim$ Poisson $\hat{\lambda}_{T} \operatorname{Gamma}=\operatorname{NegativeBinomial}\left(m, p^{*}\right)$, where $\frac{m\left(1-p^{*}\right)}{p^{*}}=\sum_{i=1}^{I} X_{i}^{*}$, then $\operatorname{Prob}\left(X_{1}, X_{2}, \ldots, X_{I} \mid p_{1}, p_{2}, \ldots, p_{I}\right)=\operatorname{Multinomial}\left(\vec{X} \mid \vec{p}, X_{T}\right) \operatorname{Neg} \cdot \operatorname{Bin}\left(X_{T} \mid \sum_{i=1}^{I} X_{i}^{*}\right)$

$$
=\left(\frac{X_{T} !}{\prod_{i=1}^{I} X_{i} !} \prod_{i=1}^{I} p_{i}^{X_{i}}\right)\left(\frac{\Gamma\left(X_{T}+m\right)}{X_{T} ! \Gamma(m)}\right)\left(1-p^{*}\right)^{X_{T}}\left(p^{*}\right)^{m}
$$

where $p_{i}=\frac{X_{i}^{*} \varepsilon}{\sum_{j=1}^{I}\left(X_{j}^{*} \varepsilon\right)}=\frac{X_{i}^{*}}{\sum_{j=1}^{I} X_{j}^{*}}$.

Typically, a multinomial's component levels are negatively correlated, because of a fixed sum. However, when the sum or total is allowed to vary as permitted here, the unconditional correlation becomes positive. Interaction of the same gamma term with all activity rates of a single household implies positive correlation in unobserved information. ${ }^{5}$ And the end result is a multivariate negative binomial structure, where each of the demands is marginally represented by a negative binomial. ${ }^{6}$ This is the stochastic structure underlying the estimates presented here. Extensions to this work may come through incorporation of other structures, such as zeroinflated negative binomial forms (e.g., Shankar et al. 1997), which permit households to exhibit 
no travel of a certain type and thus may be very reasonable when demands are narrowly defined (e.g., child-care travel for households with no children).

\section{RESULTS}

Parameter estimates are shown in Table 2. Almost all are estimated to be highly statistically significant, and overdispersion is present ( $\alpha^{7}$ is estimated to be 1.00$)$. The average optimal demand levels $\left(X_{i}^{*}\right)$ are estimated to be $1.14,0.66,0.29$, and 0.19 discretionary activities per day per household in the immediate, near, moderate, and far contours; these are quite close to the sample means of $1.08,0.62,0.28$, and 0.19 , suggesting accuracy in aggregate prediction

Median elasticity estimates are shown in Table 3; and, overall, these results appear reasonable. Discretionary-time elasticities are positive for all households and all demand types, as one would expect. And the own-travel-time elasticity estimates are generally negative - as is typical of economically "normal" goods; however, this is not the case for the nearest zone's activity participation rates, suggesting a strong time-budget effect. Most cross-time elasticities are positive, indicating substitutability (rather than complementarity) - particularly between neighboring contours. This result is consistent with expectations, since the demands have been defined across "quality" here (i.e., level of opportunity choice), rather than activity type.

Income elasticities are positive for far and moderate zone activities but negative for closer activities, suggesting that additional monies are spent on access to and consumption of discretionary activities further away, rather than near one's home. It is interesting that nearby activities are not found to be "inferior" with respect to time, but they are with respect to income (albeit to a minor extent). It may be that the quality of activities and the amount of money spent 
on them is substantially affected by income and/or wages, but rates of activity participation do not change much, given fixed time constraints. Analysis of more detailed datasets, including expenditure and price information, may resolve this question.

Quartiles of value-of-time estimates for the sampled households are also provided in Table 3. While these are of the expected magnitude and sign, the indirect utility functions underlying the estimated model is limited in its representation of income effects; this is because only one system of demand equations - derived on the basis of travel times, rather than prices has been estimated. If there are other, isolated income effects, these will impact the marginalutility-of-income estimates and thus the value-of-time estimates - as well as money-based welfare estimates. $^{8}$

\section{Hypothesis Tests}

One can test a multitude of hypotheses with the model results. For example, given fixed income and discretionary-time levels, is total travel time by a household independent of the travel-time environment? Is the total number of trips independent of income or travel times? Stated in equation form, these hypotheses are the following:

Hypothesis 1: $\quad \frac{d(\text { Total Discretionary Travel Time })}{d\left(\text { Travel Time }_{j}\right)}=\frac{d\left(2 \sum_{i} X_{i}^{*} t_{i}\right)}{d t_{j}}=0, \forall j$

Hypothesis 2: $\frac{d(\text { Discretionary Activity Participation })}{d(\text { Income })}=\frac{d\left(\sum_{i} X_{i}^{*}\right)}{d Y}=0, \forall j$

Hypothesis 3: $\frac{d(\text { Discretionary Activity Participation })}{d\left(\text { Travel Time }_{j}\right)}=\frac{d\left(\sum_{i} X_{i}^{*}\right)}{d t_{j}}=0, \forall j$. 
The results of these hypothesis tests are described here now, and quartile values for the household sample estimates are summarized in Table 4.

\section{Hypothesis 1}

While Zahavi and others (Zahavi 1979a and 1979b, Zahavi and Talvitie 1980, Zahavi and Ryan 1980, Zahavi et al. 1981) have proposed that total travel time expenditures are inelastic with respect to travel-time costs, their observations tend to be based on aggregate data and simple correlations. Thus, a hypothesis of inelastic travel-time expenditures is particularly interesting to test here, where the model is disaggregate, behaviorally based, and quite complex. However, since the present analysis considers only discretionary-activity participation and assumes round-trip travel from one's home (without the chaining of trips into tours), the test of this first hypothesis is somewhat different from Zahavi et al.'s proposition.

As suggested in Table 4, total travel time to access discretionary activities increases when the travel times to access the closer opportunities increase, indicating a dependence on these nearby activities. But the travel time tends to fall slightly when the distant opportunities become more time-consuming to access, suggesting that people substitute nearer activities for these. The overall effects are probably strongest for the nearer activities since these carry the higher elasticities and the data indicate greater rates of activity participation in the closer isoopportunity contours. Notably, all household observations call for a rejection of Hypothesis 1 , so the results are not consistent with the hypothesis.

\section{Hypothesis 2}

Somewhat remarkably, the results are of this test are negligible and the hypothesis is not rejected. However, the consistently negative sign of the derivatives suggests that total 
discretionary trip-making does not go up when income rises, ceteris paribus. However, this result does not speak to income's role in the consumption of other, more material goods; it is in this other consumption, not modeled here, that income substantially influences choice [see, e.g., Deaton (1987), Pollack and Wales (1978 \& 1980), and Stone (1954)].

\section{Hypothesis 3}

With the exception of changes in activity participation due to changes in the immediate zone's travel times, the results in Table 4 suggest that total activity response may be largely negative, though reasonably minor for small changes in travel times. While highly statistically significant, net response for most travel times is not economically significant, suggesting very stable activity-participation rates. This and the above result are consistent with Golob, Beckmann, and Zahavi's speculation that "when travel speeds increase, travelers prefer to tradeoff saved time for longer trips, rather than for more trips," and "(w)hen incomes increase, travelers tend to purchase higher speeds (such as by transferring from bus to car travel) and travel longer distances, instead of generating more trips.” (1981, p. 378)

\section{CONCLUSIONS}

There is a need for a utility-maximizing simultaneous-equations approach to a household's choice of out-of-home activity participation, subject to both time and money constraints. The methodology presented here represents a highly flexible, theoretically rigorous, and systematic approach to this problem. The explicit recognition of time budgets means that equivalent- and compensating-variation welfare measures can be computed in units of time ${ }^{9}$, not just money. And the empirical application that is illustrated here provides a working statistical 
framework for simultaneous estimation of cardinally ordered integer behaviors possessing unobserved heterogeneity.

Estimation of the underlying model produces considerable insight into household preferences and the associated activity- and travel-related trade-offs made by them. Results include estimates of income, time, own- and cross-"price" elasticities, along with response predictions due to changes in a variety of transportation-supply, land use, and demographic variables. Analysis of the 1990 Bay Area Travel Surveys using the proposed methods produces results that are consistent with expectations and illustrates the versatility of the model for hypothesis testing.

The flexibility and strong behavioral basis of the approach make it a promising new direction for travel demand modeling. And there are a variety of areas through which the methodology can be enhanced and extended. For greater realism, more flexible stochastic and preference specifications may be introduced (see, e.g., Bhat 1998, Pollack and Wales 1980, and Train 1996), intra-household decision dynamics should be recognized (e.g., Golob and McNally 1997), scheduling constraints may be incorporated (e.g., Ettema et al. 1993, Recker 1995), and trip chaining ${ }^{10}$ should be acknowledged.

The model is sufficiently flexible to include other, non-activity consumption in the system of demand equations. Location choice and vehicle ownership are two very relevant decisions warranting closer examination; inclusion of these decisions provokes endogeneity in travel times, but such behavior can be modeled jointly with activity demand. 


\section{ENDNOTES:}

\footnotetext{
${ }^{1}$ Some households may find themselves at a corner solution, with zero optimal consumption of some activities. In such a situation Roy's Identity no longer applies to all demand types at once; instead, theory suggests that an optimization over limited choice sets is undertaken and the maximized utilities of distinct scenarios are compared. This added complexity can be accommodated in the models presented here.

${ }^{2}$ Since time use is not based on observable, exogenous prices, other than wages, one cannot rely on Roy's Identity to derive a system of demand equations for time use in multiple non-work activities.

${ }^{3}$ The choice of employment boundaries for these contours is somewhat arbitrary; two key criteria were the manageable size of choice set (i.e., four contours) and distinction of access times (which averaged roughly ten minutes, 20 minutes, 30 minutes, and 40 minutes, for access to the immediate, near, moderate, and far contours). ${ }^{4}$ Since survey lengths vary from one to five days across the BATS households, a time component is included explicitly in the likelihood. In the likelihood equation used here, the multinomial portion remains the same, but the negative binomial's probability for total observed trips $\left(X_{T}\right)$ changes (as described in Kockelman 1998). The process remains a negative binomial with the same gamma term.

${ }^{5}$ The demand-centered stochastic assumptions imply something about the variation of indirect utility across households. Since the average optimal rates, $X_{i}^{*}$ 's, are derived via Roy's Identity, the gamma error component must come out of one or both of the derivatives which are used (see Eq. 3). One possible belief or assumption is that the households are well aware of their marginal utility of available time, but observe their travel-time environment with some error such that the travel time they perceive is really distributed like the inverse of a gamma random variable around the "true" or observed travel time. Another possibility is that the travel time data used to estimate the models provide the mean travel times within different neighborhoods, but the actual, household-specific travel times within that neighborhood are inversely gamma distributed around that neighborhood's mean.

${ }^{6}$ If additional stochastic flexibility is desired, the probabilities for use in a maximum-likelihood equation would almost certainly have to be computed using numerical integration or distribution simulation over the multiple of probabilities. There presently exist many examples of this technique (e.g., Train 1996, Mehndiratta 1996, and Yen et al. 1998).

${ }^{7} \alpha$ is an indicator of overdispersion because $\alpha$ equals $1 / m$, and $V(X)=E(X)+\alpha E(X)^{2}$, if $X \sim \operatorname{Neg}$.Bin. $\left(m, p^{*}\right)$.

${ }^{8}$ The income effects on demand have not been neglected by the time-based derivation of the demand equations, so these effects are present in the results (e.g., in the income elasticities of demand).

${ }^{9}$ The author knows of no empirical examples where equivalent and/or compensating variation has been quantified with anything other than a money metric, which favors policies and projects benefiting those who have the most monetary resources available [see, e.g., Heap et al. (1992) and Price (1993)]. Kockelman (1998) computes these time-based welfare measures using the presented model and methods.

${ }^{10}$ The chaining of trips into "tours" is a common phenomenon that endogenizes access times, thus complicating the analysis. Within the Bay Area Travel Surveys (BATS), 36.6\% of home-based trip tours involve more than one nonhome stop. Investigation of these tours suggests that a single destination accounts for much of each tour's travel time; additional stops contribute only marginally. A model that accommodates this form of chaining behavior is presented and analyzed in Kockelman (1998).
} 


\section{ACKNOWLEDGMENTS}

The author is grateful to the National Science Foundation, the University of California at Berkeley, and the University of California Transportation Center for their generous fellowships. Professors Mark Hansen, Daniel McFadden, and Martin Wachs provided significant insight and substantially facilitated this work. Michael Mauch, Phil Spector, and Simon Cawley were very generous with their time and programming aid. And three anonymous reviewers provided helpful comments.

\section{REFERENCES}

Becker, G. S. (1965) A Theory of the Allocation of Time. Economic Journal, 75, 493-517.

Bhat, C. R. (1998) Accommodating Flexible Substitution Patterns in Multi-Dimensional Choice Modeling: Formulation and Application to Travel Mode and Departure Time Choice.

Transportation Research B, 32, 455-466.

Caves, D. W. and Christensen, L. R. (1980) Global Properties of Flexible Functional Forms. The American Economic Review, 70, 422-432.

Chatfield, C., Ehrenberg, A.S.C. and Goodhardt, G. J. (1966) Progress on a Simplified Model of Stationary Purchasing Behaviour. Journal of the Royal Statistical Society, 129A, 317-367.

Christensen, L. R., Jorgenson, D. W. and Lau L. J. (1975) Transcendental Logarithmic Utility Functions. The American Economic Review, 65, 367-383.

Damm, D. and Lerman, S. R. (1981) A Theory of Activity-Scheduling Behavior. Environment and Planning A, 13, 703-718. 
Deaton, A. and Muellbauer, J. (1980) Economics and Consumer Behavior. Cambridge University Press, Cambridge.

Deaton, A. (1987) Estimation of Own- and Cross-Price Elasticities from Household Survey Data. Journal of Econometrics 36, 7-30.

Domencich, T. A., and McFadden, D. (1975) Urban Travel Demand: A Behavioral Analysis. North-Holland Publishing, Amsterdam.

Ettema, D., Borgers, A. and Timmermans, H. (1995) SMASH (Simulation Model of Activity Scheduling Heuristics): Empirical Test and Simulation Issues. Activity Based Approaches: Activity Scheduling and the Analysis of Activity Patterns. Eindhoven, The Netherlands.

Golob, T. F. and McNally, M. G. (1997) A Model of Activity Participation and Travel Interactions between Household Heads. Transportation Research, 31B.

Golob, T. F., Beckmann, M. J. and Zahavi, Y. (1981) A Utility-Theory Travel Demand Model Incorporating Travel Budgets. Transportation Research 15B, 375-389.

Greene, W. H. (1993) Econometric Analysis. McMillan, New York.

Hägerstrand, T. (1970) What about People in Regional Science? Regional Science Association Papers, 24, 7-21.

Hausman, J.A., Leonard, G. K. and McFadden, D. (1995) A Utility-Consistent, Combined Discrete Choice and Count Data Model: Assessing Recreational Use Losses due to Natural Resource Demand. Journal of Public Economics, 50, 1-30.

Heap, S. H., Hollis, M., Lyons, B., Sugden, R. and Weale A. (1992) The Theory of Choice: A Critical Guide. Blackwell Publishing, Oxford, U.K. 
ITE Journal (1994) Travel Demand Forecasting Processes used by 10 Large MPO's. ITE Journal, February, 32 .

Jara-Díaz, S. R. (1994) A General Micro-Model of Users' Behavior: The Basic Issues. Proceedings of the Seventh International Conference on Travel Behaviour, pp. 91-103.

Kitamura, R. (1984) A Model of Daily Time Allocation to Discretionary Out-of-Home Activities and Trips. Transportation Research 18B, 255-266.

Kockelman, K. (1998) A Utility-Theory-Consistent System-of-Demand-Equations Approach to Household Travel Choice. Ph.D. Thesis, The University of California at Berkeley, USA.

Lau, L. J. (1986) Functional Forms in Econometric Model Building. Handbook of Econometrics III, eds Z. Griliches and M.D. Intriligator. Elsevier Science, New York.

Lu, X. and Pas, E. I. (1997) A Structural Equation Model of the Relationships among SocioDemographics, Activity Participation and Travel Behavior. Paper Presented at the 76th Annual Transportation Research Board Meeting, Washington, D.C.

Mannering, F. and Winston, C. (1985) A Dynamic Empirical Analysis of Household Vehicle Ownership and Utilization. Rand Journal of Economics, 16, 215-236.

Mehndiratta, S. (1996) Time-of-Day Effects in Intercity Business Travel. Ph.D. Thesis, The University of California at Berkeley, USA.

MTC. 1996. "San Francisco Bay Area 1990 Travel Model Development Project: Compilation of Technical Memoranda." Vol. 3. Metropolitan Transportation Commission, Oakland, CA. 
Pollack, R. A. and Wales, T. J. (1978) Estimation of Complete Demand Systems from Household Budget Data: The Linear and Quadratic Expenditure Systems. The American Economic Review, 68, 348-359.

Pollack, R. A. and Wales, T. J. (1980) Comparison of the Quadratic Expenditure System and Translog Demand Systems with Alternative Specifications of Demographic Effects. Econometrica, 48, 595-612.

Price, C. (1993) Time, Discounting, and Value. Blackwell Publishing, Oxford, U.K.

Rao, B.R., Mazumdar, S., Waller, J. M. and Li, C. C. (1973) Correlation Between the Numbers of Two Types of Children in a Family. Biometrics, 29, 271-279.

Recker, W.W. (1995) The Household Activity Pattern Problem: General Formulation and Solution. Transportation Research, 29B, 61-77.

Roy, R. (1943) De l'Utilité: Contribution à la Théorie des Choix. Hermann, Paris.

Slutsky, E. (1915) Sulia Teoria del Bilancio des Consomatore. ("On the Theory of the Budget of the Consumer.") Giornale degli Economisti, 51, 1-26. English translation in 1952: Readings in Price Theory, eds. G.J. Stigler and K.E. Boulding. Chicago University Press.

Shankar, V., Albin, R., Milton, J., and Mannering, F. (1998) Evaluating Median Cross-Over Likelihoods with Clustered Accident Counts: An Empirical Inquiry Using the Random Effects Negative Binomial Model. Transportation Research Record 1635, 44-48.

Shankar, V., Milton, J., and Mannering, F. (1997) Modeling Accident Frequencies as ZeroAltered Probability Processes: An Empirical Inquiry. Accident Analysis and Prevention, 29 (6), 829-837. 
Stone, J.R.N. (1954) Linear Expenditure Systems and Demand Analysis: An Application to the Pattern of British Demand. The Economic Journal, 64, 510-527.

Train, K. and McFadden, D. (1978) The Goods/Leisure Tradeoff and Disaggregate Work Trip Mode Choice Models. Transportation Research, 12, 349-353.

Train, K., McFadden D. and Ben-Akiva, M. (1987) The Demand for Local Telephone Service: A Fully Discrete Model of Residential Calling Patterns and Service Choices. Rand Journal of Economics, 18, 109-123.

Train, K. (1996) Unobserved Taste Variation in Recreation Demand Models. Working Paper; Department of Economics, University of California, Berkeley.

Varian, H. (1992) Microeconomic Analysis, Third Edition. W.W. Norton \& Company, New York.

Yen, J., Mahmassani, H. S. and Herman R. (1998) A Model of Employee Participation in Telecommuting Programs Based on Stated Preference Data. Travel Behaviour Research:

Updating the State of Play. eds J. D. Ortúzar, D. A. Hensher, and S. R. Jara-Diaz. Pergamon, Oxford.

Zahavi, Y. (1979a) The 'UMOT' Project. Prepared for US DOT, Report No. DOT-RSPA-DPB20-79-3, Washington, D.C.

Zahavi, Y. (1979b) Travel over Time. Prepared for the US DOT, Federal Highway Administration, FHWA PL-79-004. 
Zahavi, Y. and Ryan, M. (1980) The Stability of Travel Components over Time. Transportation Research Record No. 200.

Zahavi, Y. and Talvitie, A. (1980) Regularities in Travel Time and Money Expenditures.

Transportation Research Record No. 199.

Zahavi, Y., Beckmann, M. J. and Golob, T. F. (1981) The 'UMOT'/Urban Interactions.

Prepared for U.S, DOT, Report No. DOT-RSPA-DPB-10-7, Washington, D.C. 


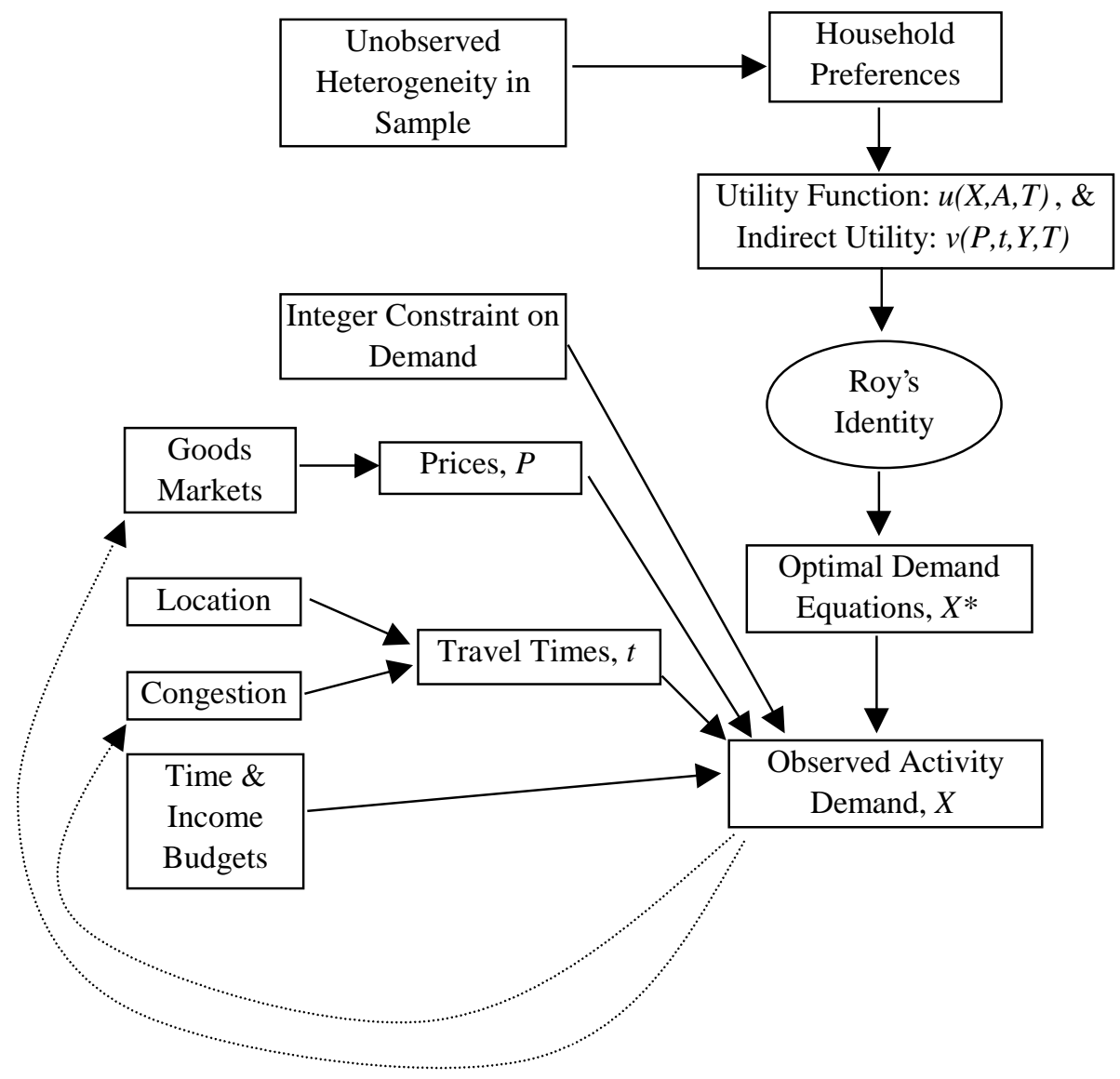

FIGURE 1. Flow Diagram of General Model Framework 
Dependent Variables:

Number of Discretionary Person Activities to the Immediate Iso-Opportunity Contour Number of Discretionary Person Activities to the Near Iso-Opportunity Contour -

Number of Discretionary Person Activities to the Moderate Iso-Opportunity Contour -

Number of Discretionary Person Activities to the Far Iso-Opportunity Contour -

Number of trips by surveyed household members (i.e., those members aged five and over) in the region on the survey day(s) for purposes of the following types: medical/dental, social, dining, recreation, grocery shopping, and non-food shopping. The four contour types/destination zones are defined below.

\section{Explanatory Variables:}

Income " $Y$ " - Pre-tax household income in 1989

Discretionary Time " $T_{d}$ " - Estimate of non-work-related and non-school time in a day available to a household's members age five and older (hours/day)

$=24 \times$ Household Size - Time in work-related $\&$ school activities

(where work \& school time are $8 \& 4$ hours per full- and part-time participant)

Travel Times to Iso-Opportunity Contours - Average total travel time by single-occupant vehicle during free-flow conditions to access successively further sets of opportunities, relative to household's home traffic analysis zone (TAZ); computed sequentially to nearest TAZs in turn, but exclusive of travel times to TAZs lying within inner, iso-opportunity contour divisions.

Contour Levels constructed at: 60,000, 300,000, 900,000 and two million total jobs, cumulatively.

\section{TABLE 1. Description of Data Set}




\begin{tabular}{|c|c|c|c|c|}
\hline Parameter & $\begin{array}{c}\text { Final } \\
\text { Estimates }\end{array}$ & $\begin{array}{c}\text { Standard } \\
\text { Errors }\end{array}$ & $\begin{array}{c}\text { T- } \\
\text { Statistics }\end{array}$ & P-Values \\
\hline$\alpha(1 / m)$ & 1.00 & 0.01 & 123 & 0.000 \\
\hline$\alpha_{1}$ & 1.53 & 1.29 & 1.2 & 0.238 \\
\hline$\alpha_{2}$ & -8.35 & 1.96 & -4.3 & 0.000 \\
\hline$\alpha_{3}$ & -9.69 & 1.74 & -5.6 & 0.000 \\
\hline$\alpha_{4}$ & -3.52 & 1.55 & -2.3 & 0.023 \\
\hline$\beta_{11}$ & -7.96 & 0.91 & -8.7 & 0.000 \\
\hline$\beta_{12}$ & -0.643 & 0.24 & -2.7 & 0.007 \\
\hline$\beta_{13}$ & -1.05 & 0.24 & -4.4 & 0.000 \\
\hline$\beta_{14}$ & -0.202 & 0.19 & -1.1 & 0.286 \\
\hline$\beta_{22}$ & -1.03 & 0.51 & -2.0 & 0.041 \\
\hline$\beta_{23}$ & -3.90 & 0.60 & -6.5 & 0.000 \\
\hline$\beta_{24}$ & 0.858 & 0.29 & 3.0 & 0.003 \\
\hline$\beta_{33}$ & 8.47 & 1.02 & 8.3 & 0.000 \\
\hline$\beta_{34}$ & -2.27 & 0.40 & -5.7 & 0.000 \\
\hline$\beta_{44}$ & 1.95 & 0.48 & 4.1 & 0.000 \\
\hline$\gamma_{1 Y}$ & 1.60 & 0.19 & 8.6 & 0.000 \\
\hline$\gamma_{2 Y}$ & 1.15 & 0.16 & 7.2 & 0.000 \\
\hline$\gamma_{3 Y}$ & -0.576 & 0.10 & -6.0 & 0.000 \\
\hline$\gamma_{4 Y}$ & -0.836 & 0.12 & -6.8 & 0.000 \\
\hline$\gamma_{I T}$ & -0.178 & 0.10 & -1.9 & 0.064 \\
\hline$\gamma_{2 T}$ & 0.913 & 0.23 & 4.0 & 0.000 \\
\hline$\gamma_{3 T}$ & 1.44 & 0.26 & 5.6 & 0.000 \\
\hline$\gamma_{4 T}$ & 1.50 & 0.28 & 5.4 & 0.000 \\
\hline$\gamma_{T Y}($ fixed $)$ & 1.00 & $\mathrm{n} / \mathrm{a}$ & $\mathrm{n} / \mathrm{a}$ & $\mathrm{n} / \mathrm{a}$ \\
\hline
\end{tabular}

TABLE 2. Parameter Estimates 


\begin{tabular}{|l|r|}
\hline VALUE ESTIMATED: & $\begin{array}{c}\text { Median } \\
\text { of Sample }\end{array}$ \\
\hline Discretionary-Time Elasticity of & \\
Demand: & 1.028 \\
Immediate Zone Demand & 0.869 \\
Near Zone & 0.678 \\
Moderate Zone & 0.706 \\
Far Zone & \\
Income Elasticity of Demand: & -0.294 \\
Immediate Zone Demand & -0.208 \\
Near Zone & 0.086 \\
Moderate Zone & 0.122 \\
Far Zone &
\end{tabular}

Cross-Time Demand Elasticities: w/r/t Time of: Immediate

Immediate Zone:

0.257

0.100

Nea

Near Zone:

Moderate Zone:

$\begin{array}{llll}0.242 & 0.832 & -2.952 & 0.442\end{array}$

Far Zone:

$\begin{array}{llll}0.047 & -0.207 & 0.383 & -1.446\end{array}$

TABLE 3. Economic Indicators: Elasticity and Value of Time Results 


\begin{tabular}{|lr|rrrr|}
\hline Derivative & & \multicolumn{4}{|c|}{ Based on Travel Time to the following Contour: } \\
Quartiles: & & Immediate & Near & Moderate & Far \\
\cline { 3 - 6 } & Minimum & 0.28 & 0.05 & -1.80 & -0.66 \\
& $25 \%$ & 2.03 & 0.40 & -0.42 & -0.18 \\
& Median & 3.25 & 0.67 & -0.30 & -0.13 \\
$75 \%$ & 4.65 & 1.00 & -0.20 & -0.09 \\
& Maximum & 17.74 & 4.71 & -0.05 & -0.03 \\
\hline
\end{tabular}

Hypothesis 1 Estimates (all are highly statistically significant)

\begin{tabular}{l|ccccc|}
\hline Derivative & Minimum & 0.25 & Median & 0.75 & Maximum \\
\cline { 2 - 6 } & $-5.34 \mathrm{E}-04$ & $-1.44 \mathrm{E}-05$ & $-8.52 \mathrm{E}-06$ & $-5.31 \mathrm{E}-06$ & $-3.95 \mathrm{E}-07$ \\
\hline
\end{tabular}

Hypothesis 2 Estimates (few are statistically significant)

\begin{tabular}{|c|c|c|c|c|c|}
\hline \multirow{2}{*}{$\begin{array}{l}\text { Derivative } \\
\text { Quartiles: }\end{array}$} & & \multicolumn{4}{|c|}{ Based on Travel Time to the following Contour: } \\
\hline & & Immediate & Near & Moderate & Far \\
\hline & Minimum & -0.157 & -0.142 & -0.096 & -0.030 \\
\hline & $25 \%$ & 0.005 & -0.021 & -0.017 & -0.010 \\
\hline & Median & 0.039 & -0.015 & -0.008 & -0.007 \\
\hline & $75 \%$ & 0.092 & -0.010 & -0.004 & -0.005 \\
\hline & Maximum & 0.917 & 0.048 & 0.011 & -0.001 \\
\hline
\end{tabular}

Hypothesis 3 Estimates (all are highly statistically significant)

\section{TABLE 4. Hypothesis Test Results}

Note: Significance tests for the non-linear-in-variables quartiles shown here use standard errors estimated via Taylor series approximations. 